\title{
Penetrating Trans-Thoracic Aortic Injury with Right Femoral Artery Bullet Embolus
}

\author{
Kiarash Mirkia*,a Roger Hughes $^{\mathrm{b}}$, James B. Daugharthy ${ }^{\mathrm{c}}$, Randall J. Feikes ${ }^{\mathrm{c}}$ and \\ Michael H. Metzler ${ }^{\mathrm{a}}$
}

\author{
${ }^{a}$ Sunrise Hospital and Medical Center and Children Hospital, Department of Surgery, Division of Trauma, Critical Care \\ and Emergency Surgery, Las Vegas, Nevada, USA \\ ${ }^{b}$ Sunrise Hospital and Medical Center and Children Hospital, Department of Radiology, Interventional Radiology, Las \\ Vegas, Nevada, USA \\ ${ }^{c}$ Sunrise Hospital and Medical Center and Children Hospital, Cardiovascular Surgery Associates, Las Vegas, Nevada, \\ USA
}

\begin{abstract}
We are describing a penetrating thoracic aortic injury and a bullet embolus into common femoral artery with unique therapeutic endovascular approach through the same artery. The patient survived due to the prompt diagnosis and treatment by a multi-disciplinary team, specialized to effectively treat such an injury with advanced techniques.
\end{abstract}

Keywords: Thoracic aortic trauma, Endovascular repair, Penetrating injury, Bullet embolus.

\section{INTRODUCTION}

Interventional procedures, arteriography and aortography in patients who have sustained penetrating aortic trauma have undergone a significant evolution in the past 10-15 years. The use and availability of multi-detector (16-slice and greater) Computer Tomography Angiography (CTA) and the necessity of implementing minimally invasive techniques (MIT) for the treatment of patients with thoracic and abdominal vascular injuries have changed patient care and trauma management [1-5]. In the past Thoracic aortic injuries (TAI) most often required emergent surgery with significant morbidity and mortality. Currently the trauma practice is changing toward minimally invasive techniques (MIT) and the fact that CTA provides accurate three-dimensional reconstruction and definitive diagnosis is making it feasible to be able to not only diagnose but also treat patients with thoracic and abdominal vascular injuries using endovascular techniques. These advancements in imaging have dramatically changed clinical practice [6-11].

In the following case we are reporting a twenty one yearold male status post two gunshot wounds, with a thoracic aortic injury and bullet embolus into his right common femoral artery managed primarily with MIT and endovascular technique.

\section{CASE REPORT}

A 21-year-old male was brought in by Emergency Medical Services status post two gunshot wounds, one in the right shoulder, and one in the right leg.

*Address correspondence to this author at the Sunrise Hospital and Medical Center and Children Hospital, Department of Surgery, Division of Trauma and Surgical Critical Care and Emergency Surgery, 3196 South Maryland Parkway, Suite 101, Las Vegas, 89109, Nevada, USA; Tel: +1 702731 8099; Fax: +1 702731 8292; E-mail: kmirkia@lumc.edu;

kmirkia67@gmail.com
Upon arrival at trauma bay, his vitals were as follows; blood pressure (BP) 188/105 millimeter $\mathrm{Hg}$, heart rate 79 beats per minute in sinus rhythm, respiratory rate 20 breaths per minute, and his temperature rectally was measured as $36^{\circ}$ Celcius.

His primary survey was unremarkable except for decreased breath sound on the right side. There was an entry wound of the bullet in the right deltoid area without an exit wound.

The second bullet had entered and exited the right thigh posteriorly without any significant neuro-vascular injury. Sensation was intact and he had palpable pulses in that leg.

His initial chest radiograph (CXR) revealed a right sided pleural fluid collection. A chest tube was inserted with an immediate return of $700 \mathrm{ml}$ blood. The right sided hemothorax was a result of the bullet wound into his right deltoid region and the subsequent penetration into the right chest and his descending thoracic aorta (1A and $2 \mathrm{~A})$. There was no bullet seen on the CXR nor one seen on the abdominal $\mathrm{x}$-ray. The right lower extremity radiograph (x-ray) showed a bullet in the right groin area.

After initial resuscitation he underwent a CTA of his chest, abdomen and pelvis, which revealed the chest tube in good position and resolved right hemothorax. There appeared to be an injury to the descending thoracic aorta, but no on-going bleeding in the chest. (Figs. 1A and 2A).

The right groin bullet appeared to be intra-vascular and had embolized from the thoracic aortic injury into the right common femoral artery (CFA) (Figs. 1B and 2B). A Doppler exam of right lower extremity revealed good flow at the ankle with biphasic signal.

He was immediately taken to the operating room and his chest, abdomen and bilateral lower extremities were prepped and draped in usual fashion. A formal angiogram was 

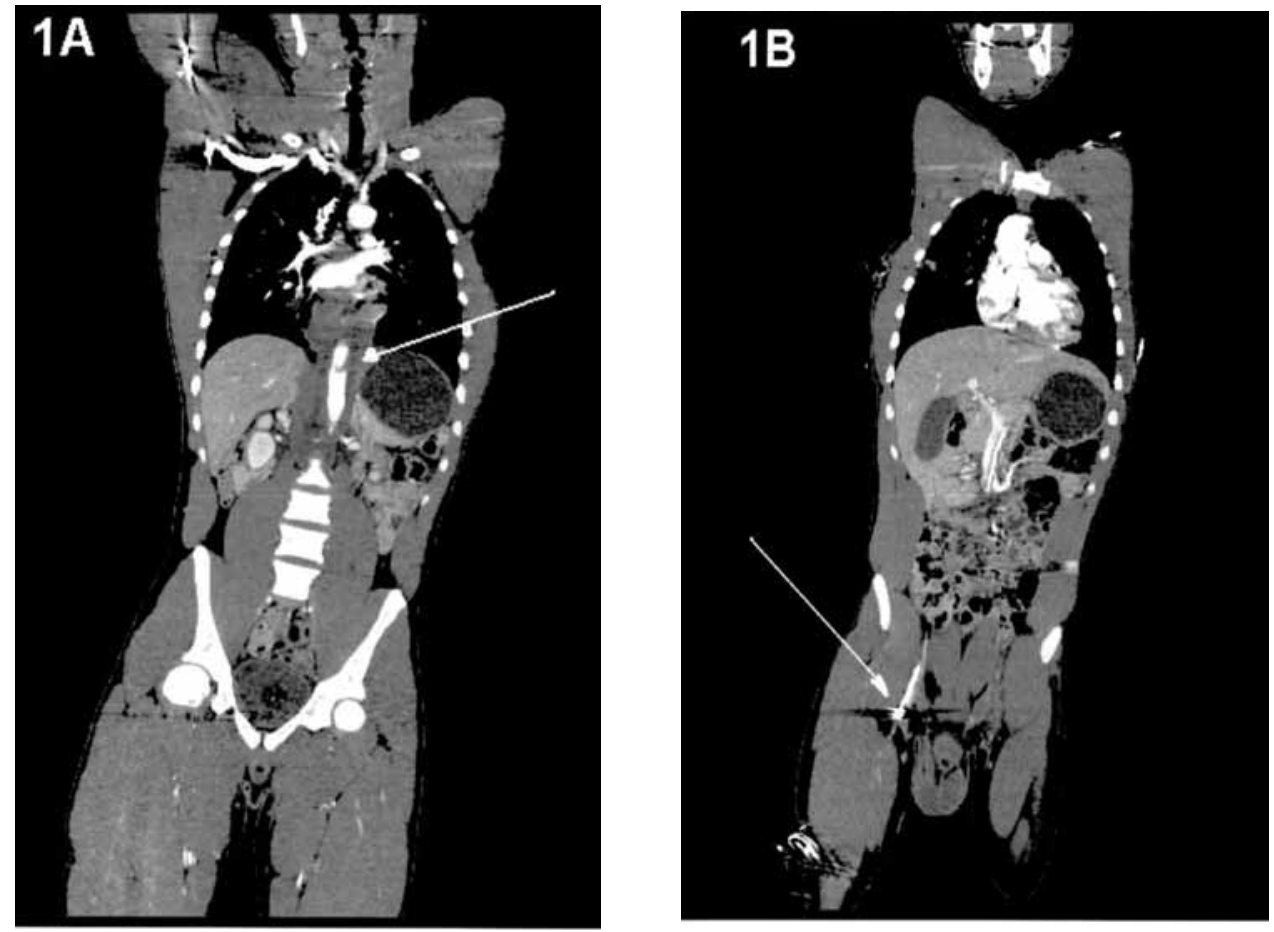

Fig. (1). Computer tomography (CT Scan) of chest/abdomen and pelvis.

(A) Reveals descending thoracic aortic injury (arrow).

(B) Shows bullet embolus in the right femoral artery (arrow).
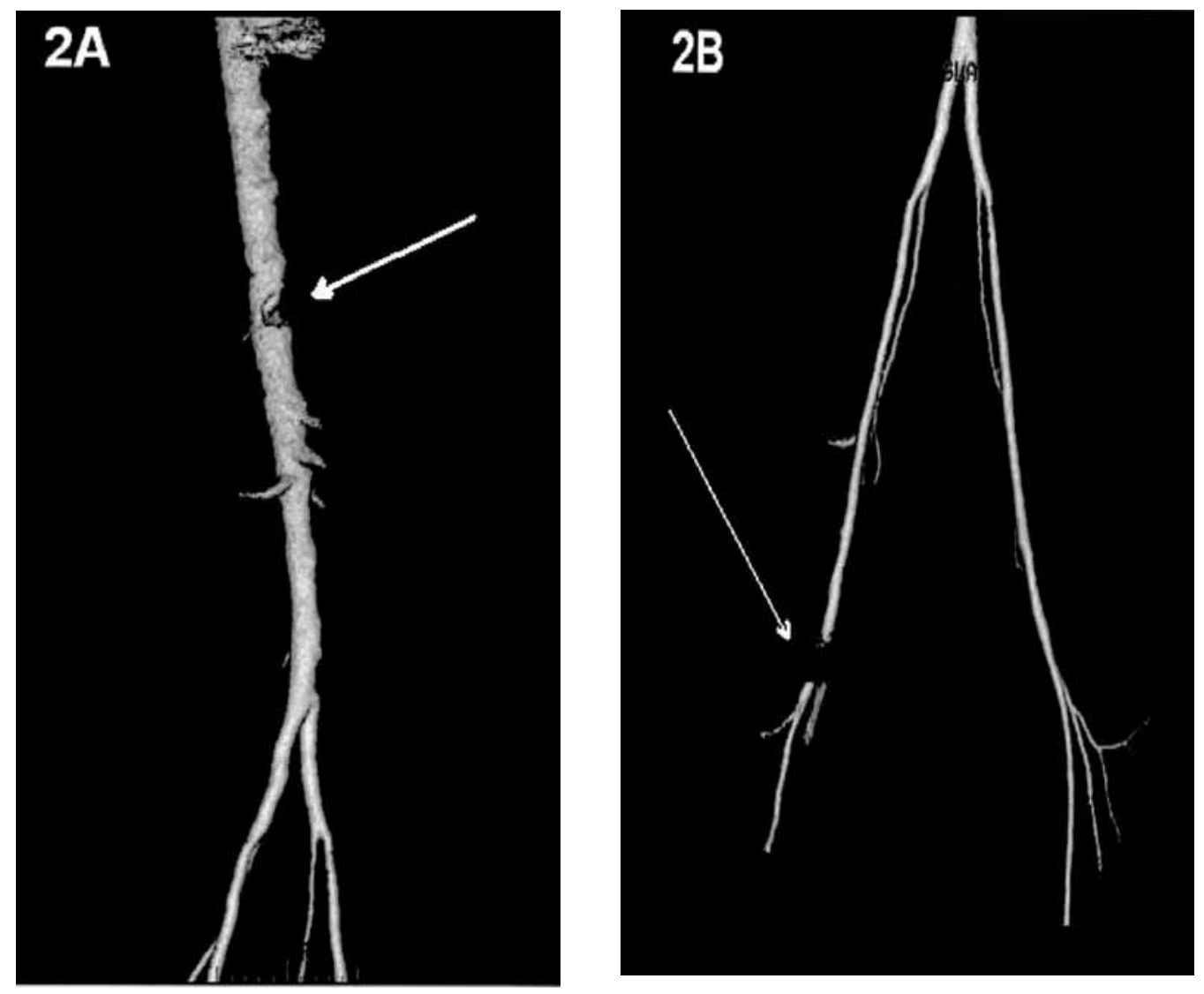

Fig. (2). Computer tomography angiography (CTA) of chest/abdomen and pelvis.

(A) Reveals a filling defect in the descending thoracic aortic (arrow).

(B) Shows a filling defect in the right common femoral artery (arrow). 

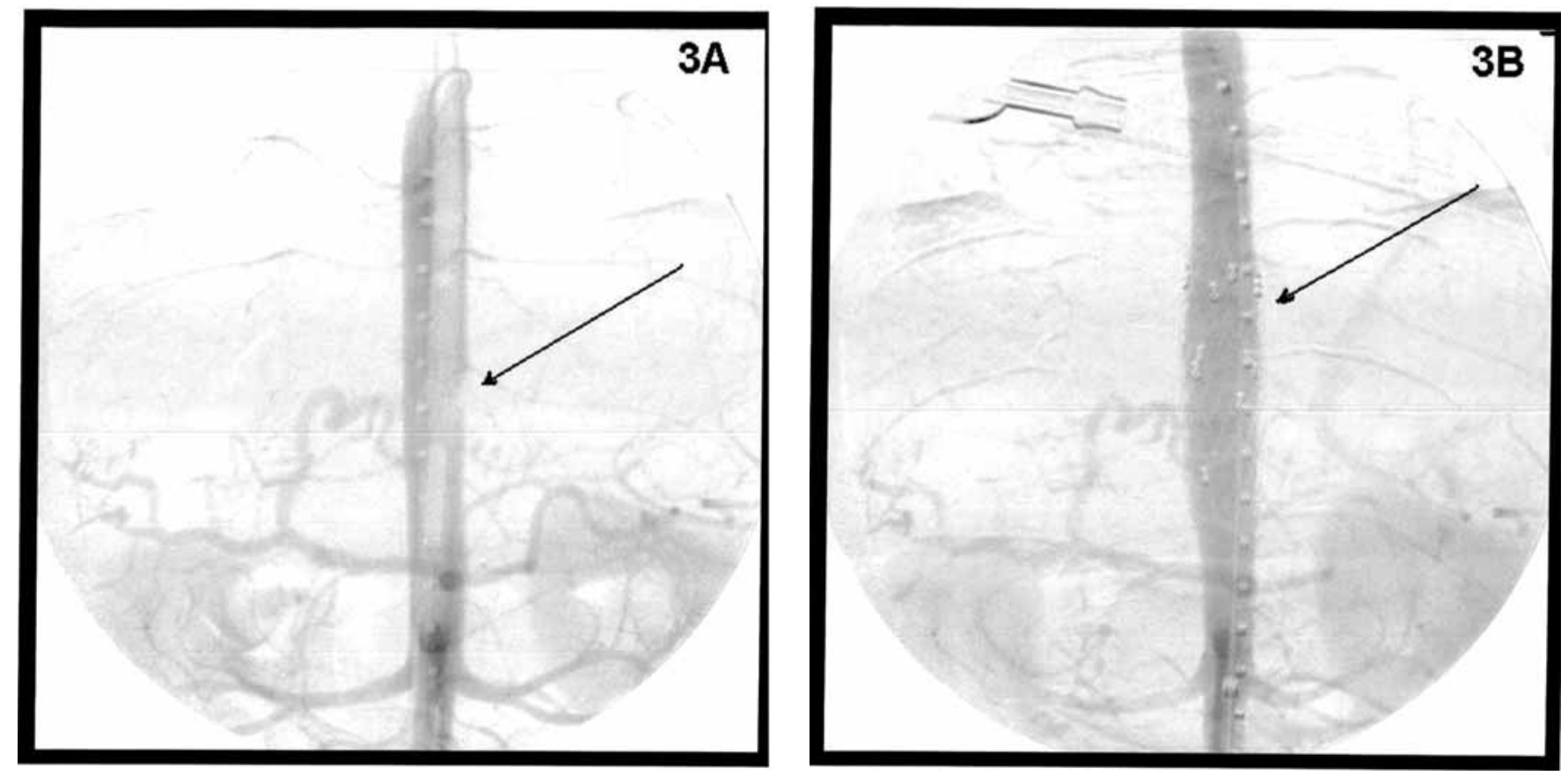

Fig. (3). Arteriography of aorta during the endovascular procedure.

(A) Illustrates the descending thoracic aortic injury (arrow).

(B) Shows endovascular repair with $24 \times 4 \mathrm{~cm}$ endograft (arrow).

performed in the operating room with confirmation of the descending thoracic aorta injury and bullet embolus into right CFA. Esophageal injury was excluded by contrast study.

Through an incision in the right groin the common, superficial and deep femoral vessels were isolated. Just distal to the origin of right CFA the bullet could be palpated inside the artery. A longitudinal arteriotomy was made after proximal and distal vessel loop controls were obtained and bullet removed. Subsequently the common femoral artery was cannulated and a guide wire was inserted. Another guide wire and angiographic catheter were inserted percutaneously via the left femoral artery which revealed the descending aorta intimal injury (Fig. 3A). Through the right femoral access a $24 \times 4 \mathrm{~cm}$ Medtronic AneuRx endograft was inserted so that it would just extend above the injury and the bottom portion extended to just below the intimal tear. It was then expanded in-place. A second $24 \times 4 \mathrm{~cm}$ endograft was then placed again via the right common femoral artery inside the first graft extended several centimeters below the injury and but well above the celiac axis and expanded and the sheaths were removed. A repeat angiogram showed full flow throughout the graft. There was no extravasation of dye seen (Fig. 3B).

Subsequently the femoral arteriotomy was extended and a Fogarty catheter was passed down both the FSA and profunda. No thrombus was noted. A $2.5 \mathrm{~cm}$ length bovine pericardial vascular patch was used and sutured over the arteriotomy using a running 6-0 Prolene suture. Subsequent Doppler and pulse check were satisfactory. Throughout the case he received 5000 units of intravenous Heparin. The incision was closed and the patient was sent to surgical intensive care unit (SICU) in stable condition.

Later that day the patient developed a compartment syndrome of the right leg, for which he underwent a fasciotomy in the operating room.

His chest tube was removed three days post-operatively. About 9 days later he underwent a split thickness skin graft on the fasciotomy wound which remained stable throughout the rest of his clinical course and has taken well. The patient was discharged home ambulating with physical therapy and tolerating regular diet without abdominal pain. The patient's overall hospital stay was 14 days.

\section{DISCUSSION}

In this report we are describing the unique diagnosis of a bullet embolus from a penetrating thoracic aortic injury into the common femoral artery and therapeutic endovascular approach through the same artery. Traumatic aortic injury is certainly a life threatening event. Early diagnosis and treatment is crucial. In our case, the diagnosis was suspected by CXR, but CTA was an effective method for evaluating the presence of thoracic aortic injury. Most thoracic aortic injuries occur as a result of blunt chest injury. Reviewing the two multi-center trials conducted by Fabian et al. comparison between the two AAST studies in 1997 and 2007 showed a major shift in the diagnosis of the aortic injury, with the widespread use of CT scan and the almost complete elimination of aortography and TEE. Endovascular repair has replaced open repair to a great extent [10-12]. In our case we were able to perform the CTA and move the patient into the operating room very quickly. The prompt diagnosis and treatment of the above patient was certainly possible due to the fact that a multi-disciplinary team was available in a designated trauma center capable of managing such an injury with advanced techniques. 


\section{CONCLUSION}

The survival of patients with penetrating major vascular injuries depends on the initial resuscitation, correct diagnostic modalities and therapeutic approach. This case report shows that in the hands of well trained clinicians under controlled environment, the minimally invasive imaging and repair techniques can decrease morbidity and mortality in a high risk trauma patient.

\section{CONFLICT OF INTEREST}

None of the authors have any financial or personal relationship with other people, or organizations, that could inappropriately influence (bias) this work within 3 years of the beginning of the study.

\section{REFERENCES}

[1] Gavant M, Menke P, Fabian T, et al. Blunt traumatic aortic rupture: detection with helical CT of the chest. Radiology 1995; 197(1): 125-33.

[2] Mirvis SE, Shanmuganathan K, Miller BH, Traumatic aortic injury: diagnosis with contrast enhanced CT: five-year experience at a major trauma center. Radiology 1996; 200(2): 413-22.

[3] Novelline R, Rhea J, Rao P, et al. Helical CT in emergency radiology. Radiology 1999; 213(2): 321-39.
Patel NH, Stephens KE, Mirvis SE, et al. Imaging of acute thoracic aortic injury due to blunt trauma: a review. Radiology 1998; 209(2): 335-48.

[5] Wicky S, Wintermark M, Denys A, et al. Radiology of blunt chest trauma. Eur Radiol 2000; 10: 1524-38

[6] Buffolo E, Palma J, Souza J, et al. Revolutionary treatment of aneurysms and dissection of the descending aorta: the endovascular approach. Ann Thorac Surg 2003; 74: S1815-7.

[7] Kramer S, Palmer R, Seifarth $\mathrm{H}$, et al. Endovascular grafting of traumatic aortic aneurysms in contaminated fields. J Endovasc Ther 2002; 8: 262-7.

[8] Marin ML, Veith FJ, Panetta TF. Transluminally placed endovascular stented graft repair for arterial trauma. J Vasc Surg 1994; 20(3): 466-73.

[9] Palma J, Miranda F, Gasques A, et al. Treatment of thoracoabdominal aneurysm with self expandable stent-grafts. Case report. Ann Thorac Surg 2002; 74: 1685-7.

[10] Fabian TC, Richardson JD, Croce MA, et al. Prospective study of blunt aortic injury: Multicenter trial of the American Association for the Surgery of Trauma. J Trauma 1997; 42(3): 374-80; discussion, 380-3.

[11] Fabian TC, Richardson JD, Groce MA, et al. Diagnosis and Treatment of Blunt Thoracic Aortic Injuries: Changing Perspectives. J Trauma-Injury Infect Crit Care 2008; 64(6): 1415-9.

[12] Fang TD, Peterson DA, Kirilcuk NN, Dicker RA, Spain DA, et al. Endovascular management of a gunshot wound to the thoracic aorta. J Trauma-Injury Infect Crit Care 2006; 60(1): 204.

(c) Mirkia et al.; Licensee Bentham Open.

This is an open access article licensed under the terms of the Creative Commons Attribution Non-Commercial License (http://creativecommons.org/licenses/by-nc/3.0/) which permits unrestricted, non-commercial use, distribution and reproduction in any medium, provided the work is properly cited. 